\title{
Obesity is associated with increased morbidity after coronary artery bypass graft surgery in patients with renal insufficiency
}

\author{
Daniel A. Tolpin, MD, ${ }^{\text {a }}$ Charles D. Collard, MD, ${ }^{\mathrm{a}}$ Vei-Vei Lee, MS, ${ }^{\mathrm{b}}$ MacArthur A. Elayda, MD, PhD, ${ }^{\mathrm{b}}$ and \\ Wei Pan, MD ${ }^{\mathrm{a}}$
}

\begin{abstract}
Objective: Although obesity is a major risk factor for cardiovascular disease, it is not clear whether obesity increases the risk of postoperative morbidity and mortality in patients undergoing coronary artery bypass grafting surgery. Increasing evidence suggests that both obesity and renal insufficiency are associated with increased systemic inflammation, thrombogenicity, and endothelial dysfunction. Cardiac surgical patients with comorbid obesity and renal insufficiency might thus be at greater risk for systemic proinflammatory and thrombotic states, which in turn might increase the risk of adverse perioperative outcomes. We investigated the influence of obesity on adverse postoperative outcomes after coronary artery bypass grafting surgery in patients with and without renal insufficiency.
\end{abstract}

\begin{abstract}
Methods: A retrospective cohort study was performed of patients $(n=10,863)$ undergoing primary coronary artery bypass grafting surgery with cardiopulmonary bypass between January 1995 and June 2005. Patients with preoperative renal insufficiency $(\mathrm{n}=1385)$ and patients with preoperative normal renal function $(\mathrm{n}=$ 9478) were further classified as obese (body mass index, $\geq 30 \mathrm{~kg} / \mathrm{m}^{2}$ ) or nonobese (body mass index, 18.5$29.9 \mathrm{~kg} / \mathrm{m}^{2}$ ). Multivariate, stepwise logistic regression was performed, controlling for demographic factors, medications, and perioperative risk factors to determine whether obesity is independently associated with an increased risk of adverse postoperative outcomes after coronary artery bypass grafting surgery in patients with or without renal insufficiency.
\end{abstract}

Results: Obese patients with preoperative renal insufficiency had higher rates of postoperative myocardial infarction $(5.9 \%$ vs $3.4 \%)$ and low cardiac output syndrome $(24.5 \%$ vs $18.6 \%)$ and increased hospital stay $(14.9 \pm$ 13.7 vs $13.2 \pm 13.0$ days) than nonobese patients with preoperative renal insufficiency (all outcomes, $P<.05$ ). Multivariate analysis revealed that obese patients with preoperative renal insufficiency were independently associated with an increased risk of postoperative myocardial infarction (odds ratio, $1.82 ; 95 \%$ confidence interval, $1.07-3.07 ; P<.05$ ) and low cardiac output syndrome (odds ratio, $1.53 ; 95 \%$ confidence interval, $1.15-2.03$; $P<.01)$ and increased hospital stay $(P<.05)$. In contrast, obese patients with normal preoperative renal function were independently associated only with an increased risk of postoperative sternal wound infection (odds ratio, $2.55 ; 95 \%$ confidence interval, $1.40-4.67 ; P<.01$ ) and leg wound infection (odds ratio, $2.27 ; 95 \%$ confidence interval, $1.71-3.02 ; P<.01)$.

Conclusion: Obesity is an independent risk factor for increased cardiovascular morbidity and prolonged hospital stay in patients with preoperative renal insufficiency undergoing primary coronary artery bypass grafting surgery.

Patients with obesity are at greater risk of atherosclerotic cardiovascular events. ${ }^{1-7}$ Recent studies suggest that obesity is associated with increased insulin resistance, endothelial dysfunction, thrombogenicity, and inflammation, which can consequently promote accelerated atherosclerosis of the microvasculature and macrovasculature. ${ }^{8-12}$ Adipose

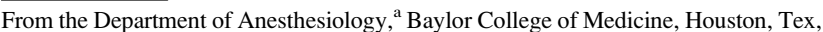
and the Division of Biostatistics and Epidemiology, ${ }^{\mathrm{b}}$ Texas Heart Institute, St Luke's Episcopal Hospital, Houston, Tex.

Received for publication March 3, 2008; revisions received Nov 4, 2008; accepted for publication Feb 2, 2009; available ahead of print April 9, 2009.

Address for reprints: Wei Pan, MD, Baylor College of Medicine, Division of Cardiovascular Anesthesiology at the Texas Heart Institute, St Luke's Episcopal Hospital, 6720 Bertner Ave, Room 0520, Houston, TX 77030 (E-mail: wpan@heart.thi.tmc. edu).

J Thorac Cardiovasc Surg 2009;138:873-9

$0022-5223 / \$ 36.00$

Copyright (C) 2009 by The American Association for Thoracic Surgery

doi:10.1016/j.jtcvs.2009.02.019
}

tissue acts as an active endocrine and paracrine organ, secreting a large number of adipokines or adipocytokines that influence metabolic and vascular processes, including leptin, adiponectin, tumor necrosis factor $\alpha$, interleukin 6 , procoagulant plasminogen activator inhibitor 1, visfatin, adipsin, angiotensinogen, resistin, and retinol-binding protein 4. ${ }^{12,13}$ It has been observed that levels of proinflammatory and procoagulation adipokines and cytokines, including leptin, P-selectin, visfatin, resistin, retinol-binding protein 4 , intercellular adhesion molecule 1 , tumor necrosis factor $\alpha$, interleukin 6 , C-reactive protein, and plasminogen activator inhibitor 1 , are increased in obese patients. ${ }^{8,9,12,14-16}$

Interestingly, persistent inflammation is highly prevalent in patients with chronic renal disease and associated with adverse outcomes. ${ }^{17}$ Axelsson and colleagues ${ }^{18,19}$ reported that circulating adipokine and adipocytokine levels are markedly increased in chronic kidney disease, likely 


$$
\begin{aligned}
& \text { Abbreviations and Acronyms } \\
& \begin{aligned}
\text { BMI } & =\text { body mass index } \\
\text { CABG } & =\text { coronary artery bypass graft } \\
\text { CI } & =\text { confidence interval } \\
\text { CPB } & =\text { cardiopulmonary bypass } \\
\text { MI } & =\text { myocardial infarction } \\
\text { OR } & =\text { odds ratio }
\end{aligned}
\end{aligned}
$$

because of decreased renal excretion. Increasing evidence also suggests that increased inflammation contributes to worsened postoperative outcomes in patients undergoing cardiopulmonary bypass $(\mathrm{CPB}) .^{20}$ Therefore cardiac surgical patients with comorbid obesity and renal insufficiency might be at greater risk for insulin resistance, endothelial dysfunction, and systemic proinflammatory and thrombotic states, which in turn might further increase their risk of adverse postoperative outcomes. We investigated the influence of obesity on adverse postoperative outcomes after primary coronary artery bypass graft (CABG) surgery with $\mathrm{CPB}$ in patients with and without renal insufficiency.

\section{MATERIALS AND METHODS Study Design}

After obtaining institutional review board approval, a retrospective cohort study was performed on all patients $(n=10,863)$ undergoing primary CABG surgery with CPB at the Texas Heart Institute, St Luke's Episcopal Hospital, Houston, Texas, between January 1995 and June 2005. Obesity was assessed by using body mass index (BMI), which was calculated as weight (in kilograms)/height (in meters squared). Patients with preoperative renal insufficiency $(\mathrm{n}=1385)$ and patients with preoperative normal renal function $(n=9478)$ were further classified into 2 groups at the time of surgical intervention by using the World Health Organization definition for obesity: a BMI of $30 \mathrm{~kg} / \mathrm{m}^{2}$ or greater for obese patients and a BMI of 18.5 to $29.9 \mathrm{~kg} / \mathrm{m}^{2}$ for nonobese patients. ${ }^{1,21}$ Underweight patients (BMI, $<18.5 \mathrm{~kg} / \mathrm{m}^{2}$ ) were excluded from the study. Patients were classified as having preoperative renal insufficiency based on either preoperative diagnosis of renal insufficiency or failure made by clinicians or a serum creatinine level of at least $2.0 \mathrm{mg} / \mathrm{dL}$ at the time of the operation. Patients undergoing concomitant valve or other cardiac surgery (eg, atrial septal defect repair or ventricular aneurysm resection) were excluded from the study.

\section{Data Collection}

Patient demographics, perioperative risk factors, and the incidence of adverse postoperative outcomes were obtained from the Texas Heart Institute cardiac surgical database. Measured adverse postoperative outcomes included 30-day all-cause mortality, myocardial infarction (MI), cardiac arrhythmias, ventilator dependence, low cardiac output syndrome, stroke, infection, and need for mediastinal re-exploration. A diagnosis of MI was made if there were either new $Q$ waves (Minnesota code 1-1-1 to 1-2-7), new persistent ST-segment or T-wave changes (Minnesota code 4-1, 4-2, 5-1, 5-2, or 9-2), an increase in serum troponin I level of greater than $10 \mathrm{ng} / \mathrm{mL}$, or clinical evidence of acute MI on autopsy. ${ }^{22}$ A diagnosis of low cardiac output syndrome was made with documented evidence of postoperative cardiogenic hypotension or shock requiring vasopressor support, use of an intra-aortic balloon pump, or both. A diagnosis of stroke was made if there was clinical evidence or evidence of a new focal or global defect on computed tomographic analysis, magnetic resonance imaging, or autopsy.

\section{Statistical Analysis}

All statistical analyses were performed with SAS statistical software (SAS Institute, Inc, Cary, NC). Patient preoperative demographics, risk factors, and preoperative medications were first compared between groups by means of univariate $\left(\chi^{2}\right)$ analysis. All predictor variables significant at a 2-tailed nominal $P$ value of less than .15 in the univariate analysis were then entered into a multivariate logistical model, and stepwise logistic regression was performed to determine whether obesity in patients with and without preoperative renal insufficiency was independently associated with an increased risk of adverse postoperative outcomes after primary CABG surgery. Only those variables significant at a 2-tailed nominal $P$ value of less than .05 were retained within the model. Odds ratios (ORs) and corresponding 95\% confidence intervals (CIs) are reported, with associated $P$ values. A c-statistic was calculated for each outcome to quantify the discriminatory power of the multivariate regression model.

In an attempt to further control for nonrandomization, propensity scores were also estimated by using unconditional logistic regression to determine the predicted probability of inclusion in the obese or nonobese group for each patient. The 24 variables used for propensity matching are shown in Tables 1 and 2. Obese $(n=3331)$ and nonobese $(n=6147)$ patients with normal preoperative renal function were then matched 1-to-1 on these variables, resulting in successful matching of 3002 patients. Similarly, obese $(n=474)$ and nonobese $(n=911)$ patients with preoperative renal insufficiency were also matched 1-to-1 on these variables, resulting in successful matching of 457 patients. All predictor variables significant at a 2 -tailed nominal $P$ value of less than .15 in the univariate analysis were then entered into a multivariate logistical model, and stepwise logistic regression was performed to determine whether obesity in propensity score-matched patients with and without preoperative renal insufficiency was independently associated with an increased risk of adverse postoperative outcomes after primary CABG surgery.

\section{RESULTS}

Patient demographics and perioperative risk factors in nonobese and obese patients with and without preoperative renal insufficiency are presented in Tables 1 and 2, respectively. Of note, the obese and nonobese groups did not significantly differ with respect to surgical urgency, history of smoking, prior MI, unstable angina, ejection fraction of less than $50 \%$, stroke, or preoperative medications in patients with or without preoperative renal insufficiency. As expected, the incidence of diabetes was significantly increased in obese compared with nonobese patients $(P<.01)$. Obese patients were also significantly younger than nonobese patients at the time of the operation $(P<.01)$. Incidences of hypertension and hyperlipidemia were higher in obese patients with or without preoperative renal insufficiency $(P<.05)$. Furthermore, aortic crossclamp and CPB times were longer in obese patients with or without preoperative renal insufficiency compared with times in nonobese patients $(P<.05)$.

The incidence of adverse postoperative outcomes in patients with normal preoperative renal function is presented in Table 3. In these patients obesity was independently associated only with increased risk of postoperative sternal wound infection (OR, 2.55; 95\% CI, 1.40-4.67; $P<.01$ ) and leg wound infection (OR, 2.27; 95\% CI, 1.71-3.02; $P<.01)$. Obesity was not independently associated with mortality, MI, arrhythmias, stroke, low cardiac output syndrome, prolonged hospital stay, or ventilator dependence. 
TABLE 1. Perioperative demographic variables and risk factors in nonobese and obese patients $(n=9478)$ without preoperative renal insufficiency undergoing primary CABG surgery

\begin{tabular}{|c|c|c|c|}
\hline Patient demographics & $\begin{array}{c}\text { BMI }<30 \mathrm{~kg} / \mathrm{m} \\
(\mathrm{n}=6147)\end{array}$ & $\begin{array}{c}\text { BMI }>30 \mathrm{~kg} / \mathrm{m}^{2} \\
(\mathrm{n}=3331)\end{array}$ & $P$ value \\
\hline Age (y) & $64 \pm 10.71$ & $60.35 \pm 10.12$ & $<.01$ \\
\hline Female sex $(\%)$ & 23 & 27 & $<.01$ \\
\hline Smoker $(\%)$ & 50 & 51 & NS \\
\hline $\begin{array}{l}\text { Urgent surgical } \\
\text { intervention }(\%)\end{array}$ & 18 & 17 & NS \\
\hline Diabetes $(\%)$ & 7 & 12 & $<.01$ \\
\hline Hypertension (\%) & 69 & 81 & $<.01$ \\
\hline Triple-vessel disease $(\%)$ & 57 & 55 & $<.05$ \\
\hline Left main disease $(\%)$ & 24 & 22 & $<.01$ \\
\hline $\begin{array}{l}\text { Prior myocardial } \\
\text { infarction }(\%)\end{array}$ & 43 & 42 & NS \\
\hline Unstable angina $(\%)$ & 54 & 54 & NS \\
\hline Ejection fraction $<50 \%(\%)$ & 38 & 36 & NS \\
\hline Valve disease $(\%)$ & 5 & 4 & NS \\
\hline $\begin{array}{l}\text { Congestive heart } \\
\text { failure }(\%)\end{array}$ & 13 & 17 & $<.01$ \\
\hline $\begin{array}{l}\text { Transient ischemic } \\
\text { attack }(\%)\end{array}$ & 4 & 3 & NS \\
\hline Stroke $(\%)$ & 6 & 5 & NS \\
\hline Pulmonary disease (\%) & 23 & 23 & NS \\
\hline Hyperlipidemia (\%) & 60 & 64 & $<.01$ \\
\hline Preoperative IABP (\%) & 4 & 4 & NS \\
\hline$\beta$-Blocker $(\%)$ & 45 & 47 & NS \\
\hline Calcium-channel blocker $(\%)$ & 25 & 28 & NS \\
\hline Aspirin $(\%)$ & 63 & 63 & NS \\
\hline Antiarrhythmics (\%) & 4 & 4 & NS \\
\hline Crossclamp time (min) & $38 \pm 20$ & $40 \pm 21$ & $<.01$ \\
\hline Total bypass time (min) & $66 \pm 30$ & $69 \pm 33$ & $<.01$ \\
\hline
\end{tabular}

Consistent with previous reports, the incidence of mediastinal re-exploration in obese patients was significantly decreased compared with that seen in nonobese patients $(5.8 \%$ vs $4.1 \%, P<.05) .{ }^{23-25}$ Interestingly, the incidence of stroke was significantly less in obese patients than in nonobese patients $(1.9 \%$ vs $2.8 \%, P<.05)$.

The incidence of adverse postoperative outcomes in patients with preoperative renal insufficiency is presented in Table 4. In contrast to patients with normal preoperative renal function, the incidence of postoperative MI $(5.9 \%$ vs $3.4 \%, P<.05)$ and low cardiac output syndrome $(24.5 \%$ vs $18.6 \%, P<.01)$, the length of hospital stay $(14.9 \pm$ 13.7 vs $13.1 \pm 13.0$ days, $P<.05$ ), and the incidence of ventilator dependence $(11.2 \%$ vs $8.0 \%, P=.052)$ and sternal wound infection $(2.3 \%$ vs $0.8 \%, P<.05)$ were significantly greater in obese patients compared with nonobese patients with univariate analysis, respectively. Furthermore, multivariate analysis revealed that obesity in patients with preoperative renal insufficiency undergoing $\mathrm{CABG}$ was independently associated with an increased risk of post-
TABLE 2. Perioperative demographic variables and risk factors in nonobese and obese patients $(n=1385)$ with preoperative renal insufficiency undergoing primary CABG surgery

\begin{tabular}{|c|c|c|c|}
\hline $\begin{array}{c}\text { Patient } \\
\text { demographics }\end{array}$ & $\begin{array}{c}\text { BMI }<30 \mathrm{~kg} / \mathrm{m} \\
(\mathrm{n}=911)\end{array}$ & $\begin{array}{c}\text { BMI }>30 \mathrm{~kg} / \mathrm{m}^{2} \\
(\mathrm{n}=474)\end{array}$ & $P$ value \\
\hline Age (y) & $66 \pm 10.3$ & $63 \pm 10$ & $<.01$ \\
\hline Female sex $(\%)$ & 23 & 29 & $<.05$ \\
\hline Smoker $(\%)$ & 52 & 52 & NS \\
\hline $\begin{array}{l}\text { Urgent surgical } \\
\text { intervention }(\%)\end{array}$ & 20 & 19 & NS \\
\hline Diabetes $(\%)$ & 14 & 21 & $<.01$ \\
\hline Hypertension (\%) & 85 & 88 & $<.05$ \\
\hline Triple-vessel disease $(\%)$ & 59 & 57 & NS \\
\hline Left main disease $(\%)$ & 27 & 25 & NS \\
\hline $\begin{array}{l}\text { Prior myocardial } \\
\text { infarction }(\%)\end{array}$ & 46 & 48 & NS \\
\hline Unstable angina $(\%)$ & 51 & 52 & NS \\
\hline Ejection fraction $<50 \%(\%)$ & 45 & 43 & NS \\
\hline Valve disease $(\%)$ & 9 & 7 & NS \\
\hline $\begin{array}{l}\text { Congestive heart } \\
\text { failure }(\%)\end{array}$ & 32 & 35 & NS \\
\hline $\begin{array}{l}\text { Transient ischemic } \\
\text { attack }(\%)\end{array}$ & 5 & 4 & NS \\
\hline Stroke $(\%)$ & 11 & 12 & NS \\
\hline Pulmonary disease $(\%)$ & 34 & 36 & NS \\
\hline Hyperlipidemia (\%) & 58 & 63 & $<.05$ \\
\hline Preoperative IABP (\%) & 4 & 5 & NS \\
\hline$\beta$-Blocker $(\%)$ & 49 & 50 & NS \\
\hline Calcium-channel blocker (\%) & 33 & 33 & NS \\
\hline Aspirin $(\%)$ & 60 & 62 & NS \\
\hline Antiarrhythmics (\%) & 7 & 5 & NS \\
\hline Crossclamp time (min) & $40 \pm 20$ & $43 \pm 25$ & $<.05$ \\
\hline Total bypass time (min) & $69 \pm 33$ & $76 \pm 42$ & $<.01$ \\
\hline
\end{tabular}

$C A B G$, Coronary artery bypass grafting; $B M I$, body mass index; $I A B P$, intra-aortic balloon pump.

operative MI (OR, 1.82; 95\% CI, 1.07-3.07; $P<.05)$ and low cardiac output syndrome (OR, $1.53 ; 95 \% \mathrm{CI}$, $1.15-2.03 ; P<.01)$ and increased length of hospital stay $(P<.05)$. In addition, there was a strong trend toward ventilator dependence $(\mathrm{OR}, 1.45 ; 95 \% \mathrm{CI}, 0.98$ 2.16; $P=.065)$ and sternal wound infection (OR, $2.30 ; 95 \%$ CI, $0.98-6.87 ; P=.06)$ in obese patients with renal insufficiency. Risk-adjusted ORs and CIs for adverse postoperative outcomes in obese patients with preoperative renal insufficiency are presented in Figure 1. The c-statistic for these outcomes ranged from 0.604 to 0.801 . No significant differences between obese and nonobese patients with preoperative renal insufficiency were observed with respect to the incidence of 30-day allcause mortality, atrial or ventricular arrhythmias, stroke, sepsis, or leg wound infection or the need for mediastinal re-exploration (Table 4).

In an attempt to further control for selection bias related to the choice of therapy, stepwise logistic regression was also performed on a propensity score-matched cohort of 6004 
TABLE 3. Postoperative outcomes in nonobese and obese patients $(n=9478)$ without preoperative renal insufficiency undergoing primary CABG surgery

\begin{tabular}{|c|c|c|c|c|c|}
\hline Postoperative outcome & $\begin{array}{c}\text { BMI }<30 \mathrm{~kg} / \mathrm{m}^{2} \\
(\mathbf{n}=6147)\end{array}$ & $\begin{array}{c}\text { BMI }>30 \mathrm{~kg} / \mathrm{m}^{2} \\
(\mathbf{n}=\mathbf{3 3 3 1})\end{array}$ & $P$ value & OR & $95 \% \mathrm{CI}$ \\
\hline 30-d mortality (\%) & 2.9 & 2.7 & NS & 0.91 & $0.69-1.20$ \\
\hline Ventilator dependence $(\%)$ & 4.2 & 4.5 & NS & 1.16 & $0.93-1.44$ \\
\hline Atrial fibrillation $(\%)$ & 20.0 & 19.1 & NS & 1.01 & $0.90-1.13$ \\
\hline Atrial flutter $(\%)$ & 6.4 & 5.9 & NS & 0.94 & $0.78-1.13$ \\
\hline Ventricular fibrillation (\%) & 3.5 & 3.1 & NS & 0.95 & $0.74-1.21$ \\
\hline Ventricular tachycardia $(\%)$ & 5.5 & 6.2 & NS & 1.13 & $0.93-1.35$ \\
\hline Low cardiac output syndrome $(\%)$ & 12.1 & 12.2 & NS & 1.02 & $0.88-1.16$ \\
\hline Stroke $(\%)$ & 2.7 & 2.0 & .03 & 0.73 & $0.54-0.97$ \\
\hline Cardiac arrest $(\%)$ & 5.0 & 4.4 & NS & 0.94 & $0.76-1.16$ \\
\hline Myocardial infarction (\%) & 3.1 & 3.4 & NS & 1.08 & $0.85-1.37$ \\
\hline Mediastinal re-exploration (\%) & 4.8 & 3.4 & .004 & 0.72 & $0.57-0.90$ \\
\hline Postoperative IABP (\%) & 4.4 & 4.5 & NS & 1.01 & $0.81-1.25$ \\
\hline Sternal wound infection $(\%)$ & 0.3 & 0.8 & .002 & 2.55 & $1.04-4.67$ \\
\hline Leg wound infection (\%) & 1.6 & 3.2 & .001 & 2.27 & $1.71-3.22$ \\
\hline Sepsis $(\%)$ & 1.6 & 1.7 & NS & 1.061 & $0.75-1.49$ \\
\hline Hospital stay (d) & $10.2 \pm 9.1$ & $10.5 \pm 8.1$ & NS & & \\
\hline
\end{tabular}

$C A B G$, Coronary artery bypass grafting; $B M I$, body mass index; $O R$, odds ratio; $C I$, confidence interval; $N S$, not significant; IABP, intra-aortic balloon pump.

patients with normal preoperative renal function and 904 patients with preoperative renal insufficiency, respectively. Even after controlling for propensity score, obesity still independently predicted an increased risk of postoperative ventilator dependence $(P<.05)$ and low cardiac output syndrome $(P<.01)$ in patients with preoperative renal insufficiency. Although the incidence of postoperative MI was not found to be significantly higher in obese patients with preoperative renal insufficiency compared with that seen in nonobese patients, there was a strong trend to suggest that obesity was associated with increased risk of postoperative MI
$(6.1 \%$ vs $3.7 \%, P=.059)$ after CABG surgery. The slight loss in statistical significance in postoperative MI with propensity analysis is most likely attributable to the loss of statistical power associated with the $35 \%$ reduction in the total original sample size after propensity matching. Furthermore, no significant differences were observed between obese and nonobese patients with preoperative renal insufficiency with respect to the incidence of 30-day all-cause mortality, atrial or ventricular arrhythmias, stroke, sepsis, or leg wound infection or the need for mediastinal re-exploration. Similar to the above non-propensity score-matched

TABLE 4. Postoperative outcomes in nonobese and obese patients $(n=1358)$ with preoperative renal insufficiency undergoing primary CABG surgery

\begin{tabular}{|c|c|c|c|c|c|}
\hline Postoperative outcome & $\begin{array}{c}\text { BMI }<30 \mathrm{~kg} / \mathrm{m}^{2} \\
(\mathrm{n}=911)\end{array}$ & $\begin{array}{c}\mathrm{BMI}>30 \mathrm{~kg} / \mathrm{m}^{2} \\
(\mathrm{n}=474)\end{array}$ & $P$ value & OR & $95 \% \mathrm{CI}$ \\
\hline 30-d mortality (\%) & 8.1 & 7.4 & NS & 0.937 & $0.60-1.47$ \\
\hline Ventilator dependence $(\%)$ & 8.0 & 11.2 & .07 & 1.451 & $0.98-2.16$ \\
\hline Atrial fibrillation (\%) & 24.6 & 20.5 & NS & 0.831 & $0.63-1.10$ \\
\hline Atrial flutter $(\%)$ & 6.0 & 7.6 & NS & 1.174 & $0.75-1.84$ \\
\hline Ventricular fibrillation (\%) & 6.2 & 6.1 & NS & 0.947 & $0.59-1.51$ \\
\hline Ventricular tachycardia (\%) & 8.1 & 10.8 & NS & 1.392 & $0.94-2.06$ \\
\hline Low cardiac output syndrome $(\%)$ & 18.6 & 24.5 & .004 & 1.526 & $1.15-2.03$ \\
\hline Stroke $(\%)$ & 4.4 & 3.0 & NS & 0.692 & $0.36-1.32$ \\
\hline Cardiac arrest $(\%)$ & 9.7 & 10.3 & NS & 1.058 & $0.72-1.55$ \\
\hline Myocardial infarction (\%) & 3.4 & 5.9 & .03 & 1.815 & $1.07-3.07$ \\
\hline Mediastinal re-exploration (\%) & 7.8 & 6.5 & NS & 0.824 & $0.53-1.29$ \\
\hline Postoperative IABP (\%) & 7.9 & 8.9 & NS & 1.178 & $0.78-1.79$ \\
\hline Sternal wound infection (\%) & 0.8 & 2.3 & .06 & 2.296 & $0.98-6.87$ \\
\hline Leg wound infection $(\%)$ & 2.9 & 4.0 & NS & 1.588 & $0.86-2.95$ \\
\hline Sepsis & 2.6 & 4.0 & NS & 1.473 & $0.77-1.49$ \\
\hline Hospital stay (d) & $13.2 \pm 13.0$ & $14.9 \pm 13.7$ & .04 & & \\
\hline
\end{tabular}

$C A B G$, Coronary artery bypass grafting; $B M I$, body mass index; $O R$, odds ratio; $C I$, confidence interval; $N S$, not significant; $I A B P$, intra-aortic balloon pump. 


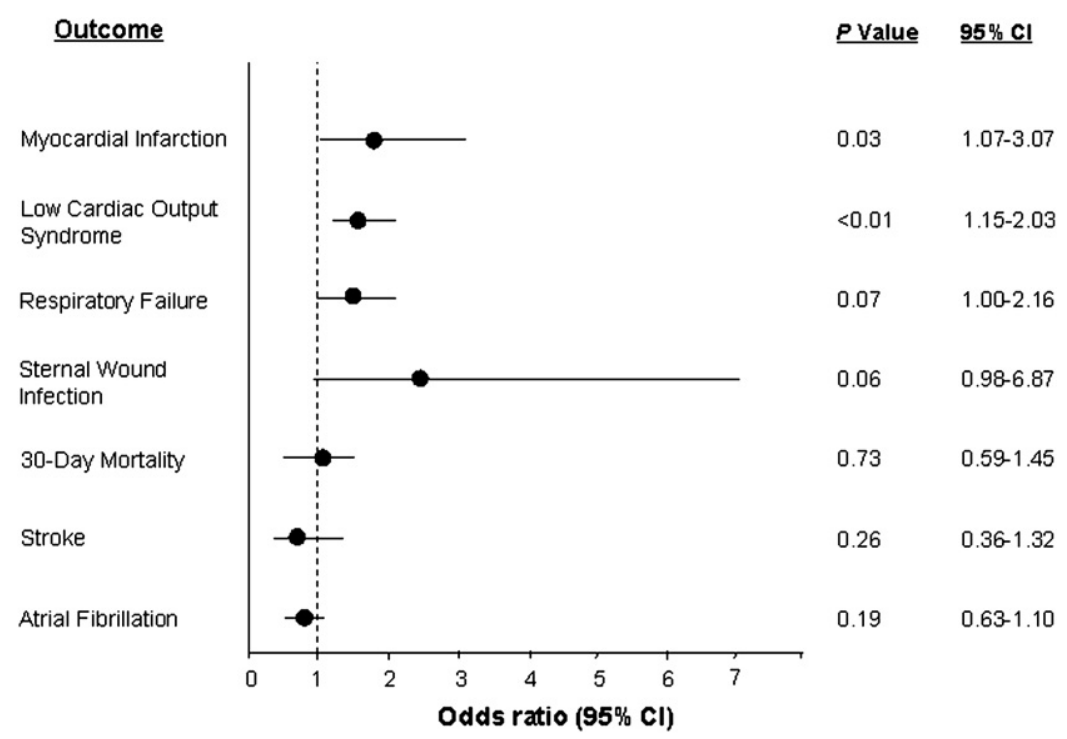

FIGURE 1. Multivariate analysis of adverse postoperative outcomes after primary coronary artery bypass grafting surgery in obese patients with preoperative renal insufficiency, controlling for patient demographics, perioperative risk factors, and medications. Significant independent predictors of adverse postoperative outcomes, along with their associated odds ratios and $95 \%$ confidence intervals $(C I)$, are shown.

analyses, propensity score-matched cohort analyses showed that obesity was independently associated only with increased incidence of sternal infection $(P<.05)$ and leg wound infection $(P<.01)$ in patients with normal preoperative renal function. Nonetheless, multivariate stepwise logistic regression with or without propensity score matching demonstrated that obesity in patients with preoperative renal insufficiency was an independent predictor of an increased risk of postoperative cardiovascular morbidity after CABG surgery, although not in obese patients without preoperative renal insufficiency.

\section{DISCUSSION}

Although obesity is recognized as a major risk factor for cardiovascular disease, it is not clear whether obesity increases the risk of perioperative morbidity and mortality in patients undergoing CABG surgery. Multiple clinical studies have investigated whether obesity is an independent predictor of postoperative cardiovascular morbidity and mortality after CABG surgery. However, many clinical studies have failed to demonstrate that obesity is independently associated with an increased risk of postoperative morbidity, including death, MI, stroke, and renal failure. ${ }^{23,24,26}$ Our previous study suggested that although obesity was associated with minimal perioperative risk in nondiabetic patients undergoing $\mathrm{CABG}$ surgery, it was a significant independent predictor of worsened postoperative outcomes in diabetic patients. ${ }^{25}$ We now demonstrate that obesity in patients with normal preoperative renal function undergoing primary CABG surgery is not independently associated with an increased risk of postoperative death, MI, arrhythmias, stroke, or prolonged hospital stay. However, obese patients with preoperative renal insufficiency are almost twice as likely to have a postoperative MI $(5.9 \%$ vs $3.4 \%, P<.05)$ than nonobese patients with preoperative renal insufficiency. Obese patients with preoperative renal insufficiency are also more likely to have postoperative low cardiac output syndrome $(24.5 \%$ vs $18.6 \%, P<.01)$ and to have lengthened hospital stays $(14.9 \pm 13.7$ vs $13.2 \pm 13.0$ days, $P<$ .05) compared with nonobese patients with preoperative renal insufficiency. In addition, there was a strong trend toward ventilator dependence $(11.2 \%$ vs $8.0 \%, P=.065)$ and sternal wound infection $(2.3 \%$ vs $0.8 \%, P=.06)$ in obese patients with renal insufficiency. Together, these data strongly suggest that obesity in conjunction with renal insufficiency confers an increased risk of worsened postoperative outcomes in patients undergoing primary $\mathrm{CABG}$ surgery.

Common to both obesity and renal insufficiency is an underlying systemic chronic inflammatory state. Multiple studies have shown increased levels of inflammatory markers in patients with obesity, the metabolic syndrome, or both. $^{1,8,9,12,13}$ Notably, there is strong evidence supporting a role for increased markers of inflammation and increased rates of atherosclerosis and coronary events. ${ }^{8,9,13,28-30}$ Similar to the obesity literature, there are several studies that report increased levels of inflammatory cytokines in patients with renal insufficiency. ${ }^{31-36}$ Systemic inflammation in patients with renal insufficiency is also associated with activated markers of coagulation, which might increase the risk of thrombotic events. ${ }^{35}$ Increasing evidence suggests that increased inflammation contributes to worsened postoperative outcomes in patients undergoing $\mathrm{CPB} .{ }^{20}$ Therefore patients with both obesity and renal insufficiency might also be at 
greater risk of adverse postoperative outcomes after CABG surgery with CPB. Supporting this hypothesis is our observation that obesity in the presence of preoperative renal insufficiency was independently predictive of increased incidence of postoperative MI and low cardiac output syndrome and prolonged hospital stay after CABG surgery. Moreover, obesity was not independently associated with increased risk of cardiovascular morbidity or prolonged hospital stay in the absence of preoperative renal insufficiency.

Previous studies examining the effect of obesity on adverse postoperative outcomes after cardiac surgery have yielded conflicting results. Although several studies have suggested that obesity is associated with an increased risk of postoperative mortality, ${ }^{37-39}$ respiratory failure, ${ }^{25,40}$ and atrial arrhythmias, ${ }^{25,27,40}$ other investigations have failed to confirm these findings. ${ }^{23,24,26}$ However, none of these previous studies specifically investigated the effect of obesity in patients with preoperative renal insufficiency versus patients without preoperative renal insufficiency. In our cohort, obesity was independently associated only with increased risk of postoperative sternal and leg wound infection in patients with normal preoperative renal function. In contrast, obesity was independently associated with an increased risk of postoperative MI and prolonged hospital stay in patients with preoperative renal insufficiency. Consistent with our previous study, obesity is not independently associated with postoperative mortality in patients undergoing CABG surgery. Recently, Wagner and coworkers ${ }^{39}$ reported that BMI was independently predictive of operative mortality and morbidity, with a U-shape relationship. Both very low and very high BMI affected both mortality and morbidity after CABG surgery. Interestingly, this predictive $\mathrm{U}$-shape relationship for both mortality and morbidity was flattened out in the absence of insulin-controlled diabetes, indicating that some of the risk associated with high BMI is attributable to the increased incidence of diabetes. Our previous study also suggested that obesity poses minimal perioperative risk in nondiabetic patients undergoing CABG surgery, whereas obesity in diabetic patients is an independent predictor of worsened postoperative outcomes. ${ }^{25}$ Nevertheless, obesity alone might be a weak independent predictor of cardiovascular mortality or morbidity after CABG surgery. However, in the context of renal insufficiency or diabetes, obesity can then become a significant independent predictor of postoperative outcomes after CABG surgery.

Although this retrospective cohort study extends the results of previous studies by suggesting that obesity in the setting of renal insufficiency is an independent risk factor for postoperative morbidity after CABG surgery, the present study is not without limitations.

First, patient enrollment in our study was neither prospective nor randomized. Despite the use of logistic regression models and propensity score matching to adjust for potential confounders that might affect postoperative outcomes, immeasurable or unknown factors might still exist.

Second, data of "preoperative renal insufficiency" were entered into the database by data abstractors based on criteria of either preoperative diagnosis of renal insufficiency or failure made by clinicians or a serum creatinine level of at least $2.0 \mathrm{mg} / \mathrm{dL}$ at the time of the operation. We are unable to quantify the severity of renal insufficiency or separate patients with dialysis-dependent renal failure from those with renal insufficiency without dialysis-dependent renal failure.

Third, the relatively low number of patients with renal insufficiency in our case series might have limited our ability to detect independent and significant associations between obesity and low-frequency adverse outcomes. Indeed, there was a strong trend toward ventilator dependence $(11.2 \%$ vs $8.0 \%, P=.065)$ and sternal wound infection $(2.3 \%$ vs $0.8 \%, P=.06$ ) in obese patients with renal insufficiency. However, the difference did not reach statistical significance. Further research with appropriately designed prospective trials is thus necessary to evaluate the effect of obesity on surgical outcomes in these subpopulations. Data obtained from such studies might improve perioperative risk stratification and resource use.

In conclusion, obesity appears to confer a greater risk of postoperative cardiovascular morbidity, but not mortality, after primary $\mathrm{CABG}$ surgery in patients with preoperative renal insufficiency.

\section{References}

1. Poirier P, Giles TD, Bray GA, et al. Obesity and cardiovascular disease: pathophysiology, evaluation, and effect of weight loss: an update of the 1997 American Heart Association Scientific Statement on Obesity and Heart Disease from the Obesity Committee of the Council on Nutrition, Physical Activity, and Metabolism. Circulation. 2006;113:898-918.

2. Bray GA, Bellanger T. Epidemiology, trends, and morbidities of obesity and the metabolic syndrome. Endocrine. 2006;29:109-17.

3. Wang TJ, Parise H, Levy D, et al. Obesity and the risk of new-onset atrial fibrillation. JAMA. 2004;292:2471-7.

4. Rimm EB, Stampfer MJ, Giovannucci E, et al. Body size and fat distribution as predictors of coronary heart disease among middle-aged and older US men. Am J Epidemiol. 1995;141:1117-27.

5. Manson JE, Willett WC, Stampfer MJ, et al. Body weight and mortality among women. N Engl J Med. 1995;333:677-85.

6. Kenchaiah S, Evans JC, Levy D, et al. Obesity and the risk of heart failure. N Engl J Med. 2002;347:305-13.

7. Alpert MA. Obesity cardiomyopathy: pathophysiology and evolution of the clinical syndrome. Am J Med Sci. 2001;321:225-36.

8. Eckel RH, Barouch WW, Ershow AG. Report of the National Heart, Lung, and Blood Institute-National Institute of Diabetes and Digestive and Kidney Diseases Working Group on the pathophysiology of obesity-associated cardiovascular disease. Circulation. 2002;105:2923-8.

9. Rader DJ. Inflammatory markers of coronary risk. $N$ Engl J Med. 2000;343: 1179-82.

10. Loskutoff DJ, Samad F. The adipocyte and hemostatic balance in obesity: studies of PAI-1. Arterioscler Thromb Vasc Biol. 1998;18:1-6.

11. Goldhaber SZ, Grodstein F, Stampfer MJ, et al. A prospective study of risk factors for pulmonary embolism in women. JAMA. 1997;277:642-5.

12. Van Gaal LF, Mertens IL, De Block CE. Mechanisms linking obesity with cardiovascular disease. Nature. 2006;444:875-80.

13. Lau DC, Dhillon B, Yan H, et al. Adipokines: molecular links between obesity and atherosclerosis. Am J Physiol Heart Circ Physiol. 2005;288:H2031-41. 
14. Reilly MP, Lehrke M, Wolfe ML, et al. Resistin is an inflammatory marker of atherosclerosis in humans. Circulation. 2005;111:932-9.

15. Pontiroli AE, Pizzocri P, Koprivec D, et al. Body weight and glucose metabolism have a different effect on circulating levels of ICAM-1, E-selectin, and endothelin1 in humans. Eur J Endocrinol. 2004;150:195-200.

16. Mertens I, Considine RV, Van der Planken M, et al. Hemostasis and fibrinolysis in non-diabetic overweight and obese men and women. Is there still a role for leptin? Eur J Endocrinol. 2006;155:477-84.

17. Stenvinkel P, Ketteler M, Johnson RJ, et al. IL-10, IL-6, and TNF-alpha: central factors in the altered cytokine network of uremia - the good, the bad, and the ugly. Kidney Int. 2005;67:1216-33.

18. Axelsson J, Heimburger O, Stenvinkel P. Adipose tissue and inflammation in chronic kidney disease. Contrib Nephrol. 2006;151:165-74.

19. Axelsson J, Stenvinkel P. Role of fat mass and adipokines in chronic kidney disease. Curr Opin Nephrol Hypertens. 2008;17:25-31.

20. Pintar T, Collard CD. The systemic inflammatory response to cardiopulmonary bypass. Anesthesiol Clin North Am. 2003;21:453-64.

21. World Health Organization. Obesity: preventing and managing the global epidemic. Report of a WHO consultation. World Health Organ Tech Rep Ser. 2000;894:1-12.

22. Pan W, Pintar T, Anton J, Lee VV, Vaughn WK, Collard CD. Statins are associated with a reduced incidence of perioperative mortality after coronary artery bypass graft surgery. Circulation. 2004;110(suppl 1):II45-9.

23. Birkmeyer NJ, Charlesworth DC, Hernandez F, et al. Obesity and risk of adverse outcomes associated with coronary artery bypass surgery. Northern New England Cardiovascular Disease Study Group. Circulation. 1998;97:1689-94.

24. Kim J, Hammar N, Jakobsson K, et al. Obesity and the risk of early and late mortality after coronary artery bypass graft surgery. Am Heart J. 2003;146:555-60.

25. Pan W, Hindler K, Lee VV, et al. Obesity in diabetic patients undergoing coronary artery bypass graft surgery is associated with increased postoperative morbidity. Anesthesiology. 2006;104:441-7.

26. Christakis GT, Weisel RD, Buth KJ, et al. Is body size the cause for poor outcomes of coronary artery bypass operations in women? J Thorac Cardiovasc Surg. 1995; 110:1344-56.

27. Kuduvalli M, Grayson AD, Oo AY, et al. Risk of morbidity and in-hospital mortality in obese patients undergoing coronary artery bypass surgery. Eur $J$ Cardiothorac Surg. 2002;22:787-93.
28. Wolk R, Berger P, Lennon RJ, et al. Body mass index: a risk factor for unstable angina and myocardial infarction in patients with angiographically confirmed coronary artery disease. Circulation. 2003;108:2206-11.

29. Ridker PM, Rifai N, Pfeffer M, et al. Elevation of tumor necrosis factor-alpha and increased risk of recurrent coronary events after myocardial infarction. Circulation. 2000;101:2149-53.

30. Ridker PM, Rifai N, Stampfer MJ, et al. Plasma concentration of interleukin-6 and the risk of future myocardial infarction among apparently healthy men. Circulation. 2000;101:1767-72.

31. Stenvinkel P, Lindholm B, Heimburger M, et al. Elevated serum levels of soluble adhesion molecules predict death in pre-dialysis patients: association with malnutrition, inflammation, and cardiovascular disease. Nephrol Dial Transplant. 2000; 15:1624-30

32. Panichi V, Migliori M, De Pietro S, et al. C-reactive protein as a marker of chronic inflammation in uremic patients. Blood Purif. 2000;18:183-90.

33. Panichi V, Migliori M, De Pietro S, et al. C-reactive protein and interleukin-6 levels are related to renal function in predialytic chronic renal failure. Nephron. 2002;91:594-600.

34. Tonelli M, Sacks F, Pfeffer M, et al. Biomarkers of inflammation and progression of chronic kidney disease. Kidney Int. 2005;68:237-45.

35. Mezzano D, Espana F, Panes O, et al. Increased activation of protein C, but lowe plasma levels of free, activated protein $\mathrm{C}$ in uraemic patients: relationship with systemic inflammation and haemostatic activation. Br J Haematol. 2001;113: 905-10.

36. Axelsson J, Heimburger O, Lindholm B, et al. Adipose tissue and its relation to inflammation: the role of adipokines. J Ren Nutr. 2005;15:131-6.

37. Edwards FH, Carey JS, Grover FL, et al. Impact of gender on coronary bypass operative mortality. Ann Thorac Surg. 1998;66:125-31.

38. Prabhakar G, Haan CK, Peterson ED, et al. The risks of moderate and extreme obesity for coronary artery bypass grafting outcomes: a study from the Society of Thoracic Surgeons' database. Ann Thorac Surg. 2002;74:1125-30.

39. Wagner BD, Grunwald GK, Rumsfeld JS, et al. Relationship of body mass index with outcomes after coronary artery bypass graft surgery. Ann Thorac Surg. 2007; 84:10-6.

40. Habib RH, Zacharias A, Schwann TA, et al. Effects of obesity and small body size on operative and long-term outcomes of coronary artery bypass surgery: a propensity-matched analysis. Ann Thorac Surg. 2005;79:1976-86. 